\title{
Selective inferior petrosal sinus sampling without venous outflow diversion in the detection of a pituitary adenoma in Cushing's syndrome
}

\author{
Lukas Andereggen • Gerhard Schroth • Jan Gralla • Rolf Seiler • Luigi Mariani • \\ Jürgen Beck • Hans-Rudolf Widmer • Robert H. Andres • Emanuel Christ • \\ Christoph Ozdoba
}

Received: 19 April 2011 / Accepted: 7 July 2011 /Published online: 2 August 2011

(C) Springer-Verlag 2011

\begin{abstract}
Introduction Conventional MRI may still be an inaccurate method for the non-invasive detection of a microadenoma in adrenocorticotropin (ACTH)-dependent Cushing's syndrome (CS). Bilateral inferior petrosal sinus sampling (BIPSS) with ovine corticotropin-releasing hormone (oCRH) stimulation is an invasive, but accurate, intervention in the diagnostic armamentarium surrounding CS. Until now, there is a continuous controversial debate regarding lateralization data in detecting a microadenoma. Using BIPSS, we evaluated whether a highly selective placement of microcatheters without diversion of venous outflow might improve detection of pituitary microadenoma.

Methods We performed BIPSS in 23 patients that met clinical and biochemical criteria of CS and with equivocal MRI findings. For BIPSS, the femoral veins were catheterized bilaterally with a 6-F catheter and the inferior petrosal sinus bilaterally with a $2.7-\mathrm{F}$ microcatheter. A third catheter was placed in the right femoral
\end{abstract}

\footnotetext{
L. Andereggen $\cdot$ G. Schroth $\cdot$ J. Gralla $\cdot$ C. Ozdoba $(\bowtie)$

University Institute of Diagnostic and Interventional

Neuroradiology, Bern University Hospital,

Freiburgstrasse 4,

3010 Bern, Switzerland

e-mail: christoph.ozdoba@insel.ch

L. Andereggen $\cdot$ R. Seiler $\cdot$ L. Mariani $\cdot$ J. Beck $\cdot$ H.-R. Widmer $\cdot$

R. H. Andres

Department of Neurosurgery, Bern University Hospital,

Bern, Switzerland

E. Christ

Division of Endocrinology, Diabetology and Clinical Nutrition, Bern University Hospital,

Bern, Switzerland
}

vein. Blood samples were collected from each catheter to determine ACTH blood concentration before and after oCRH stimulation.

Results In 21 patients, a central-to-peripheral ACTH gradient was found and the affected side determined. In 18 of 20 patients where transsphenoidal partial hypophysectomy was performed based on BIPSS findings, microadenoma was histologically confirmed. BIPSS had a sensitivity of $94 \%$ and a specificity of $67 \%$ after oCRH stimulation in detecting a microadenoma. Correct localization of the adenoma was achieved in all Cushing's disease patients.

Conclusion BIPSS remains the gold standard in the detection of a microadenoma in CS. Our findings show that the selective placement of microcatheters without venous outflow diversion might further enhance better recognition to localize the pituitary tumor.

Keywords Angiography, Digital subtraction · Cushing disease $\cdot$ Petrosal sinus sampling $\cdot$ Pituitary gland $\cdot$ Magnetic resonance imaging

\section{Introduction}

Cushing's syndrome (CS) is a hormonal disorder characterized by an increase in circulating cortisol. Endogenous hypercortisolism may be adrenocorticotropin (ACTH) dependent (pituitary or an ectopic source) or independent (related to the anatomy of the adrenal glands) [1, 2]. ACTH-dependent pituitary disease (Cushing's disease, CD) is responsible for about two thirds of Cushing's syndrome [3-5]. It is most frequently caused by a microadenoma (diameter $<10 \mathrm{~mm}$ ) $[5,6]$, less frequently by a macro- 
adenoma (diameter $>10 \mathrm{~mm}$ ) or hyperplasia of corticotrophin cells $[5,7,8]$, and rarely by carcinoma of the pituitary gland [9-11]. In contrast to pituitary-dependent CS, ectopic CS is a rare condition [12].

Differentiating between $\mathrm{CD}$ and ectopic ACTH syndrome (EAS) is a diagnostic challenge as they show similar clinical and biochemical features [13]. Due to the small size, a pituitary lesion can only be detected in about $50 \%$ of imaging studies [12, 14-17]. Furthermore, the differential diagnosis of a pituitary incidentaloma vs. an ACTHsecreting microadenoma can be challenging $[13,18,19]$.

Since the majority of patients with CD can be treated by transsphenoidal microsurgery and has a remission rate of $80-90 \%$ [5], it is critical to confirm the pituitary etiology of hypercortisolism and precisely localize the pituitary microadenoma preoperatively.

Digital imaging studies are often not sufficient for the unambiguous identification of microadenomas; both computerized tomography (CT) and magnetic resonance imaging (MRI) with standard sequences have a rather low sensitivity for these tumors: CT scan $15-60 \%[20,21]$ and MRI $60 \%$, respectively [22]. Conventional spin echo gadolinium-enhanced MRI with fine cuts through the sella turcica is nevertheless indicated in all patients with ACTHdependent Cushing syndrome [13, 23] and allows detection of a discrete adenoma in $50 \%$ to $60 \%$ of patients [22]. Spoiled gradient-recalled acquisition sequences can increase this sensitivity to approximately $80 \%$ [4]. Dynamic contrast-enhanced MRI may improve imaging accuracy [24-26] given that adenomas in comparison to normal pituitary gland parenchyma tend to be slowly enhancing. Furthermore, coronal postcontrast SPGR-MRI images showed to better differentiate microadenoma than conventional SE-MRI imaging protocols of the pituitary gland in patients with suspected Cushing disease [27]. Recently, Portocarrero et al. showed that a half-dose gadolinium protocol in dynamic 3-T MRI may further increase the sensitivity of MRI detection of ACTH-secreting pituitary tumors [28]. Nevertheless, false-negative MR results due to microadenomas that are still too small to detect by current imaging are common. In addition, approximately $10 \%$ of the normal population without any symptoms had incidentalomas in radiological series [29]. Therefore, bilateral inferior petrosal sinus sampling (BIPSS) before and following corticotropin-releasing hormone (oCRH) stimulation remains the gold standard to distinguish $\mathrm{CD}$ from EAS $[30,31]$. This procedure is included in the diagnostic algorithm for CS in current guidelines [32]. Whether BIPSS is capable to localize the correct side of the pituitary adenoma - in addition to confirm the central etiology of hypercortisolism - remains a controversial issue [33-35]. Thus, the aim of the current study was to evaluate the influence of microcatheters for the petrosal sinus sampling without flow diversion in the accurate detection of the origin of ACTH secretion.

\section{Material and methods}

Study patients

We retrospectively analyzed the accuracy of a highly selective placement of microcatheters without diversion of venous outflow in patients with Cushing syndrome and ambiguous conventional MRI findings, who were referred to our institution from June 1997 to January 2010. All patients fulfilled the diagnostic criteria of Cushing's syndrome, specifically the clinical features, biochemical tests with measurement of plasma cortisol, 24-h free cortisol in the urine, ACTH values, and a high-dose dexamethason suppression test before BIPSS.

Study procedures

\section{Magnetic resonance imaging}

In all patients, a pituitary conventional $1.5-\mathrm{T}$ MRI was performed. The standard protocol included a PD/T2-weighted whole-brain study with 5-mm slice thickness.

Both unenhanced and contrast-enhanced overlapping $3 \mathrm{~mm}$ studies in sagittal and coronal plane over the sellar region were conducted.

\section{BIPSS}

BIPSS was performed when the MRI was suspected as normal or inconclusive for a pituitary process and when the biochemical results indicated Cushing's disease.

Twenty patients were examined using neuroradiological angiography with a biplane system; in three patients, the angiographic examination was conducted using an Axiom Artis Zee including 3D rotational angiography. All procedures were performed by two senior interventional neuroradiologists.

In all but one patient, local anesthesia at the femoral puncture sites was used prior to the BIPSS procedure. In patient no. 13, general anesthesia was required because of the young age at examination date. The femoral veins were catheterized bilaterally with a 6-F catheter and heparin was used in the flushing fluid for systemic anticoagulation. The tips of these catheters were placed in the internal jugular veins. The 2.7-F microcatheters were guided under fluoroscopic control into both petrosal sinuses. This was possible in 15 out of 16 patients; however, in one case, the right catheter remained in the proximal internal jugular vein. The pattern of venous drainage was determined on each side after contrast injection. The venous drainage of the petrosal 
sinus in the jugular vein was classified as one of five drainage patterns including four common variants [36] and a fifth rather rare variant [37], where the inferior petrosal sinus connects far below the jugular bulb into the jugular vein (Figs. 1 and 2).

In seven patients, the exact type of venous drainage could only be identified from the written report because of loss of the angiography films. The position of the catheter tip was controlled before and after the venous sinus petrosal sampling (Fig. 3).

Venous blood was sampled simultaneously from both petrosal sinuses and the peripheral vein. Two baseline values were taken followed by the administration of a bolus of oCRH $(1 \mu \mathrm{g} / \mathrm{kg}$ body weight). In all three catheters, i.e., both petrosal sinuses and the peripheral vein, venous blood was sampled simultaneously for the measurement of ACTH at 3, 5, and 10 min after oCRH injection.

After the procedure, patients were observed neurologically for $24 \mathrm{~h}$ in our department.

\section{ACTH gradients}

The average ratio of ACTH values before and after oCRH administration was used to calculate the gradients needed for detecting the source of cortisol depletion. A central-toperipheral gradient $\geq 2.0$ at baseline, or $\geq 3.0$ after oCRH stimulation was regarded as indicating a pituitary source of ACTH production according to Oldfield et al. [31]. An intersinus gradient $\geq 1.4$ was evidence of right-left lateralization, an intersinus gradient $<1.4$ showed either bilateral disease or a midline lesion [38].

\section{Results}

\section{Patients}

Briefly, the study included 23 patients (18 women, five men; mean age 47 years, age range 7-70 years). A full description of the study patients can be found in Table 1 .

\section{MRI studies}

In eight out of the 23 patients, MRI identified the microadenoma correctly compared with the histopathological findings after surgery as standard of reference (patient no: 1, 4, 7, 8, 17, 18, 22, and 23). In one patient (no. 6), a pituitary adenoma was recognized by MRI but the side of the pathologic process could not be identified. The pituitary was correctly recognized as normal (true-negative result) in two patients (no. 3 and 14). In 12 patients, a false result was identified. There were four false-positive findings (no. 2, 9, 11, and 15) and eight false-negative results (cases 5, 10, 12, 13, 16, 19,20 , and 21). These findings resulted in $52.9 \%$ sensitivity and $33.3 \%$ specificity for MRI to detect a pituitary microadenoma compared with the histopathologcial findings.

\section{Catheterization procedure}

The variants of the venous drainage that describe the pattern of flow from the petrosal sinus into the jugular vein are shown in Figs. 1 and 2. Twenty-one of 23 patients were correctly diagnosed by BIPSS in terms of the central to peripheral gradient. In all cases with a central lesion, a correct lateralization was made. However, in one patient (no. 17) the required value of 1.4 after oCRH stimulation was marginally beneath the required cut-off, namely 1.339 , yet we decided to take this result as sufficient for the lateralization.

In patient no. 3, the result of the central to peripheral gradient showed a false-positive value compared with the histopathological result. In the latter, no microadenoma could be identified postoperatively, therefore an adrenalectomy was performed.

Patient no. 4 (false-negative result) had a central to peripheral vein ratio less than needed for the diagnosis of CD. Nevertheless, pituitary surgery was performed because of a strong clinical suspicion of CD and an MRI result that revealed a suspicious pathological intrasellar lesion interpreted as a microadenoma on the right side. At surgery, a
Fig. 1 Schematic representation of the variations of inferior petrosal sinus drainage into the internal jugular vein: types 1-4 modified after Shiu et al. [36] and type 5 variant described by Benndorf and Campi [37]

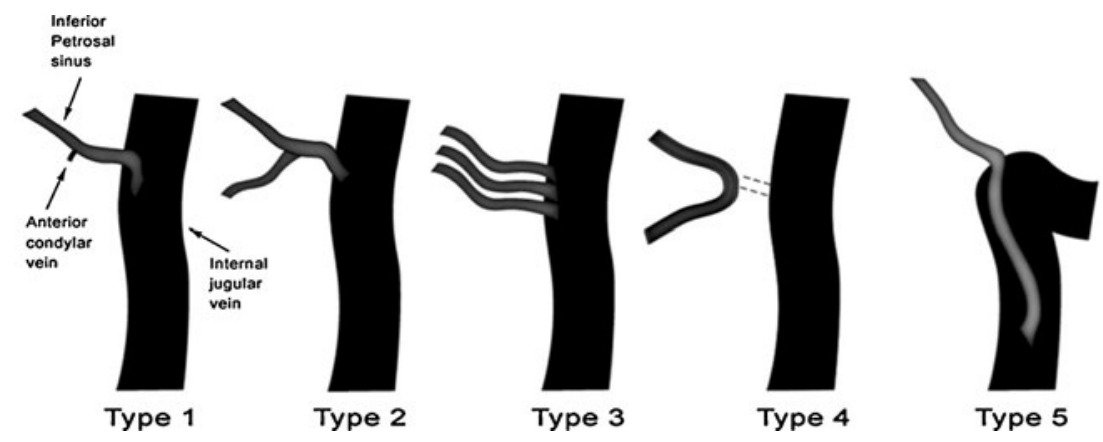




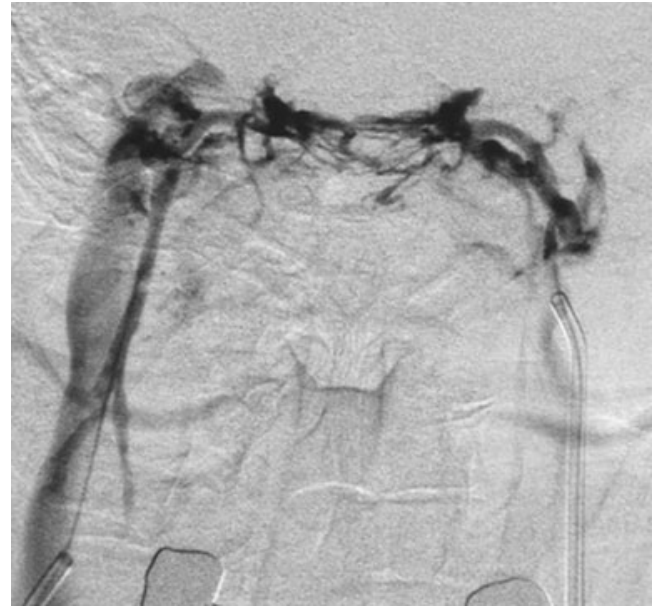

Fig. 2 Angiography of drainage variant type 5. Uncommonly low origin of the inferior petrosal sinus from the right jugular vein on the right side. The intercavernous sinus is depicted as well. Awareness of this infrequent venous pattern may help to better identify the successful approach to the cavernous sinus

small tumor was found and histopathologically confirmed (Table 1).

Of the 20 patients with $\mathrm{CD}$, a central to peripheral gradient suggesting $\mathrm{CD}$ was already obtained before oCRH in 17 patients, two additional patients showed a gradient greater than 3.0 after CRH application (no. 10 and 15). In one patient (no. 4), a false-negative result was obtained (see previous description above).

Three patients showed an ectopic localization of the ACTH source regarding BIPSS result (no. 2, 4, and 14): patient no. 2 and 14 showed a true-negative result whereas patient no. 4 had a false-negative result. In the CD group of 20 patients, an intersinus gradient $>1.4$ was found (16 patients before oCRH application and in four patients after (no. 10, 17, 22, and 23)).

No serious complications occurred during and after the invasive procedure.

\section{Surgical technique}

In 20 patients with suspected CD as a result of BIPSS, transsphenoidal surgery for adenoma extirpation was performed. Briefly, surgery was performed via a unilateral transseptal transsphenoidal approach while in the semisitting position. Above all, especially in cases where a hyperplasia in the histological examination was found, the intraoperative adenoma tissue was frequently difficult to differentiate or a suspicious brighter tissue could be demarcated. In these cases, according the result of BIPSS, one third of the lateral adenoma tissue was extirpated. Afterwards, the cavity was filled with gelatin foam soaked in fibrin glue, and the sellar opening was covered with a
Fig. 3 BIPSS procedure. A Digital subtraction angiography of the inferior petrosal sinus shows 6-F guiding catheters in the internal jugular veins (white arrows) and 2.7-F microcatheters in the petrosal sinuses (black arrows). B Similar angiogram as shown in (A) with simultaneous contrast filling of both inferior petrosal sinus as well as the intercavernous sinus. Images (C and $\mathbf{D})$ depict the same venous pattern in a $3 \mathrm{D}$ rotational angiography
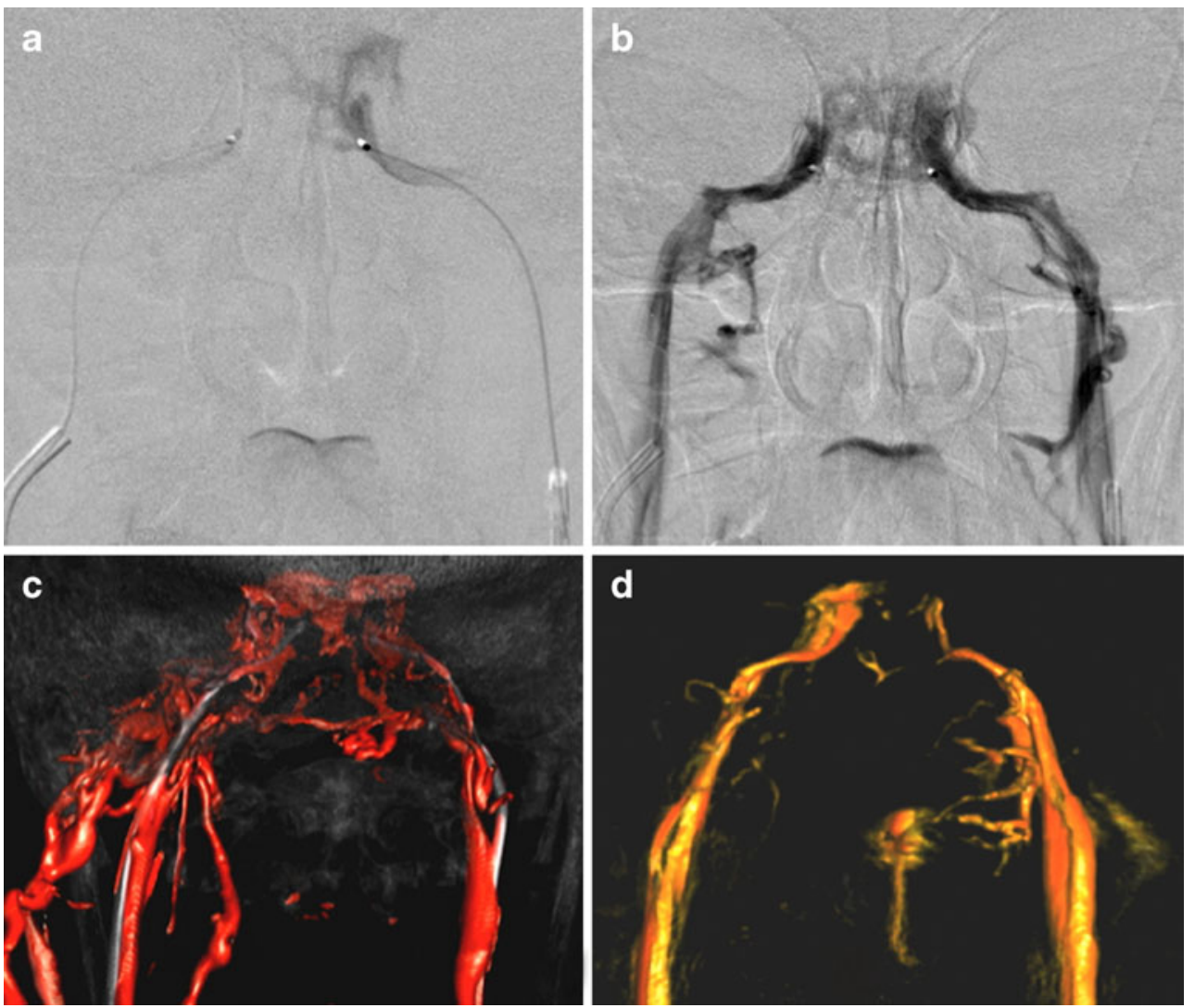


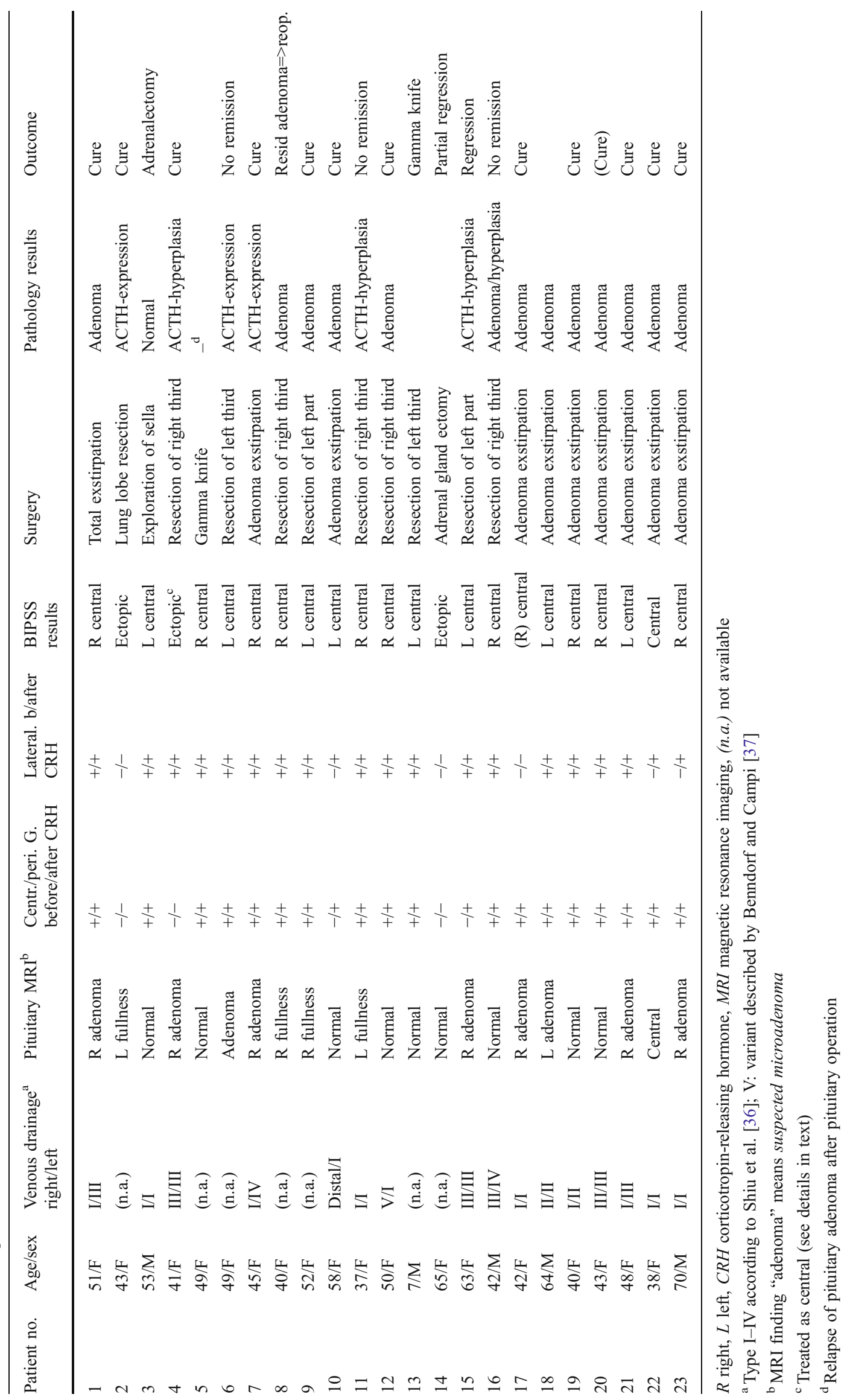


synthetic absorbable vicryl patch as described in the literature [39].

\section{Histopathological results}

In the 20 patients where a central adenoma was suspected using BIPSS, a transsphenoidal surgery was performed. Hyperplasia of ACTH-producing cells or an adenoma was observed in 18 of the 20 histopathological samples. In one patient (no. 13), a histological evaluation was not made because of loss of the histological material.

In the patient with highly suspected $\mathrm{CD}$, gamma knife irradiation of the pituitary gland was performed and the patient had a favorable outcome.

In the three patients with an ectopic source of ACTH expression (no. 2, 4, and 14), histology confirmed the localization of ACTH expression: one patient (no. 2) had a lung lobe resection and ACTH expression was identified by histology, another patient had a doublesided adrenalectomy (no. 14) causing a remission, and the treatment of the third patient (no. 4, false-negative result) has been previously discussed. Of note, histopathological confirmation of an ACTH-secreting adenoma strongly correlates with remission [40].

\section{Clinical outcomes}

The clinical outcome of the 23 patients analyzed with BIPSS was favorable in the majority of cases: 15 patients showed postoperative normalization of the hypercortisolism with favorable clinical development, one patient showed partial regression (no. 14), and three patients showed no remission (no. 6, 11, and 16). Two patients had a gamma knife treatment with no available long-term result to date (no. 5 and 13). Patient no. 3 had adrenalectomy because the BIPSS results revealed a pituitary process, but surgery showed no adenoma and finally, patient no. 8 had a reoperation because of a residual adenoma of the pituitary.

\section{Statistical analyses}

The BIPSS procedure allowed the correct differentiation between CD and EAS in $82.4 \%$ and $95.0 \%$ of patients before and after oCRH stimulation, respectively. The specificity of the BIPSS procedure before and after oCRH stimulation was $66.7 \%$ respectively. Correct lateralization could be made in all cases of CD (100\%).

\section{Discussion}

There is considerable controversy in regards to the accuracy of the side of pituitary lesion using BIPSS data [41]. In the present study, BIPSS was able to correctly localize the side of the adenoma in all patients with CD. Of the examined 20 patients with $\mathrm{CD}$, an intersinus gradient $>1.4$ was achieved in $80 \%$ of the cases before and in $100 \%$ after oCRH stimulation even if an asymmetric venous drainage was documented. This is consistent with the study of Oliverio et al. [42]. They reported in a series of 17 patients that bilateral cavernous sinus sampling (BCSS) enabled the identification of the correct side in all patients, yielding a positive predictive value of $100 \%$. The author concluded that this result might be due to the potential of cavernous sinus sampling to more accurately lateralize the lesion. However, Doppman et al. [43] reported correct lateralization in patients with CD using BIPSS in $60 \%$ of the cases without and in $73 \%$ of the cases with oCRH stimulation. Newell-Price et al. [34] found that CD can be distinguished from EAS with a diagnostic accuracy close to $100 \%$ when BIPSS is combined with oCRH stimulation. On the other hand, the intersinus gradient correctly predicted the localization of the pituitary adenoma in only $78 \%$ of the cases.

These controversial findings may be related to the different venous drainage pattern [41]. Lefournier et al. [44] reported that three parameters influenced the lateralization result, i.e., venous drainage pattern, sampling site, and oCRH stimulation. Friedman et al. [45] performed the procedure in adults with $\mathrm{CD}$ and healthy volunteers and found that the correct lateralization side was the side of the dominant petrosal sinus.

However, in the current study asymmetric venous drainage did not influence the lateralization data. Due to the fact that we detected $80 \%$ accuracy before and $100 \%$ accuracy after stimulation, we assume that compensatory and regulatory mechanism on the contra-lateral side of the adenoma may have influenced the hormone levels. Furthermore, for all patients we selectively placed the microcatheter in the petrosal sinus, which does not disturb the venous blood flow in both petrosal sinus and the cavernous sinus. In contrast, the placement of catheters with relatively large diameter influences the drainage pattern by obstructing the venous outflow around the catheter. This may result in retrograde blood flow through the intercavernous sinus leading to false-positive values on the opposite side of the lesion. In addition, digital subtraction angiography was performed to assure the correct catheter placement and to document the anatomical venous pattern drainage. Microcatheters allow a normal blood flow without influencing the venous blood flow even in asymmetric drainages. This also may minimize complications such as thromboembolism or perforations. We conclude that the use of microcatheters result in significantly improved measured ACTH concentrations on the effective side of the lesion. We propose that digital subtraction angiography should be performed to 
assure the correct catheter placement for documenting the exact anatomical venous pattern drainage. This allows for a critical and comprehensive analysis of the anatomy with the obtained biochemical cortisol levels.

Additionally, it is established that the diagnostic performance of BIPSS is superior to pituitary imaging in ACTHdependent hypercortisolism to distinguish between $\mathrm{CD}$ and ectopic ACTH-dependent hypercortisolism. The current findings are consistent with previous results $[30,31,46$, 47] showing a superior sensitivity and specificity of BIPSS compared with MRI (95\% to $52.9 \%$ and $66.7 \%$ to $33.3 \%$, respectively). Most pituitary macroadenomas can be detected by MRI. CD, however, is mostly caused by microadenomas so that it is often difficult or even impossible to determine a pathologic intrasellar process.

There were no severe complications in the current study suggesting that this invasive procedure is safe in experienced hands. However, in previous studies several major complications such as pulmonary thromboembolism [15, 41, 42] and lower extremity deep venous thrombosis [48] have been reported. In addition, Lefournier et al. [44] described two cases of transient sixth cranial nerve palsy during BCSS. They attributed these incidents to the guide wire of the catheter and suggest that BCSS might be less safe than BIPSS. Graham et al. [49] performed cavernous sinus sampling (CSS) with $2.7-\mathrm{F}$ microcatheters and compared it with results of inferior petrosal sinus sampling. They found that CSS was superior to IPSS for intrapituitary tumor localization and no complication occurred in their series of 70 patients. Recent results suggest that BIPSS is not inferior to BCSS with regard to correct lateralization of a microadenoma. This view is consistent with the studies of Doppman [43], Mamelak [41], and Lefournier [44]. In a recent study published by Gandhi et al. [50], one serious complication of irreversible brain stem injury in a study of 44 patients who underwent BIPSS for evaluation of Cushing's disease was described. In this rare case, there was radiographic evidence of venous outflow variance that may have contributed to the injury. They concluded that venous hypertension as a result of catheter-related occlusion of a venous channel or from the pressure or toxicity of contrast injection probably resulted in the pontine infarction.

\section{Study limitations}

In seven out of 23 subjects, no angiogram films were available so that the type of drainage had to be estimated from the written report which limits exact reconfirmation of catheter position.

We had no control group in our study comparing selective catheterization versus a more proximal nonselective venous blood sampling. This would allow direct comparison of the influence of microcatheters in this specific setup and would also be technically possible; however, two major concerns limit this approach. First, measurement of ACTH concentrations 3, 5, and $10 \mathrm{~min}$ after oCRH stimulation had to be measured two times with an already attained peak of ACTH concentration after the first stimulation. Second, prolonged catheter placement in the venous system bears the danger of possible thrombus formation with consecutive thromboembolism even under continuous heparin infusion during the procedure. Additionally, our patient collective still represents a relatively small sample and would not be definitive.

\section{Conclusion}

BIPSS remains the gold standard in the detection of a microadenoma in CS. Supporting selective placement of microcatheters without venous outflow diversion may play an important role in accurate detection of the origin of ACTH secretion. Therefore, this super-selective catheterization technique provides a firm basis in the assessment of CS caused by a non-detectable microadenoma of the pituitary.

Acknowledgments We especially thank Josef Rohrer from the Department of Neuroradiology for his excellent technical assistance to the interventional procedures; Daniela Miescher, Department of Neurosurgery, for her wonderful drawing of the different drainage patterns; Verena Grimm from the Department of Endocrinology for collecting blood samples; and Susan Wieting for medical editing of the final version of this manuscript, Department of Neurosurgery, Publications Office, Bern Switzerland.

Conflict of interest We declare that we have no conflict of interest.

\section{References}

1. Howlett TA, Drury PL, Perry L, Doniach I, Rees LH, Besser GM (1986) Diagnosis and management of ACTH-dependent Cushing's syndrome: comparison of the features in ectopic and pituitary ACTH production. Clin Endocrinol (Oxf) 24:699-713

2. Imöhl MSA, Krieg M (2003) Diagnose und differentialdiagnose des Cushing-Syndroms. J Lab Med 27(1/2):43-52

3. Findling JW, Doppman JL (1994) Biochemical and radiologic diagnosis of Cushing's syndrome. Endocrinol Metab Clin North Am 23:511-537

4. Kaye TB, Crapo L (1990) The Cushing syndrome: an update on diagnostic tests. Ann Intern Med 112:434-444

5. Mampalam TJ, Tyrrell JB, Wilson CB (1988) Transsphenoidal microsurgery for Cushing disease. A report of 216 cases. Ann Intern Med 109:487-493

6. Fahlbusch R, Buchfelder M, Muller OA (1986) Transsphenoidal surgery for Cushing's disease. J R Soc Med 79:262-269

7. Cushing H (1932 (1994)) The basophil adenomas of the pituitary body and their clinical manifestations (pituitary basophilism). Obes Res 2:486-508 
8. Kruse A, Klinken L, Holck S, Lindholm J (1992) Pituitary histology in Cushing's disease. Clin Endocrinol (Oxf) 37:254-259

9. Gabrilove JL, Anderson PJ, Halmi NS (1986) Pituitary proopiomelanocortin-cell carcinoma occurring in conjunction with a glioblastoma in a patient with Cushing's disease and subsequent Nelson's syndrome. Clin Endocrinol (Oxf) 25:117-126

10. Kaiser FE, Orth DN, Mukai K, Oppenheimer JH (1983) A pituitary parasellar tumor with extracranial metastases and high, partially suppressible levels of adrenocorticotropin and related peptides. J Clin Endocrinol Metab 57:649-653

11. Nawata H, Higuchi K, Ikuyama S, Kato K, Ibayashi H, Mimura K, Sueishi K, Zingami H, Imura H (1990) Corticotropin-releasing hormone and adrenocorticotropin-producing pituitary carcinoma with metastases to the liver and lung in a patient with Cushing's disease. J Clin Endocrinol Metab 71:1068-1073

12. Trainer PJ, Grossman A (1991) The diagnosis and differential diagnosis of Cushing's syndrome. Clin Endocrinol (Oxf) 34:317330

13. Boscaro M, Arnaldi G (2009) Approach to the patient with possible Cushing's syndrome. J Clin Endocrinol Metab 94:31213131

14. Dickstein G, DeBold CR, Gaitan D, DeCherney GS, Jackson RV, Sheldon WR Jr, Nicholson WE, Orth DN (1996) Plasma corticotropin and cortisol responses to ovine corticotropinreleasing hormone $(\mathrm{CRH})$, arginine vasopressin (AVP), CRH plus $\mathrm{AVP}$, and CRH plus metyrapone in patients with Cushing's disease. J Clin Endocrinol Metab 81:2934-2941

15. Newell-Price J, Perry L, Medbak S, Monson J, Savage M, Besser M, Grossman A (1997) A combined test using desmopressin and corticotropin-releasing hormone in the differential diagnosis of Cushing's syndrome. J Clin Endocrinol Metab 82:176-181

16. Orth DN (1995) Cushing's syndrome. N Engl J Med 332:791-803

17. Trainer PJBG (1995) Cushing's syndrome. The Bart's endocrine protocols. Churchill Livingstone, London, In, pp 84-92

18. Kaskarelis IS, Tsatalou EG, Benakis SV, Malagari K, Komninos I, Vassiliadi D, Tsagarakis S, Thalassinos N (2006) Bilateral inferior petrosal sinuses sampling in the routine investigation of Cushing's syndrome: a comparison with MRI. AJR Am J Roentgenol 187:562-570

19. Tabarin A, Laurent F, Catargi B, Olivier-Puel F, Lescene R, Berge J, Galli FS, Drouillard J, Roger P, Guerin J (1998) Comparative evaluation of conventional and dynamic magnetic resonance imaging of the pituitary gland for the diagnosis of Cushing's disease. Clin Endocrinol (Oxf) 49:293-300

20. Buchfelder M, Nistor R, Fahlbusch R, Huk WJ (1993) The accuracy of CT and MR evaluation of the sella turcica for detection of adrenocorticotropic hormone-secreting adenomas in Cushing disease. AJNR Am J Neuroradiol 14:1183-1190

21. Saris SC, Patronas NJ, Doppman JL, Loriaux DL, Cutler GB Jr, Nieman LK, Chrousos GP, Oldfield EH (1987) Cushing syndrome: pituitary CT scanning. Radiology 162:775-777

22. Boscaro M, Barzon L, Fallo F, Sonino N (2001) Cushing's syndrome. Lancet 357:783-791

23. Arnaldi $\mathrm{G}$, Angeli A, Atkinson AB, Bertagna $\mathrm{X}$, Cavagnini $\mathrm{F}$, Chrousos GP, Fava GA, Findling JW, Gaillard RC, Grossman AB, Kola B, Lacroix A, Mancini T, Mantero F, Newell-Price J, Nieman LK, Sonino N, Vance ML, Giustina A, Boscaro M (2003) Diagnosis and complications of Cushing's syndrome: a consensus statement. J Clin Endocrinol Metab 88:5593-5602

24. Bartynski WS, Lin L (1997) Dynamic and conventional spin-echo MR of pituitary microlesions. AJNR Am J Neuroradiol 18:965972

25. Gao R, Isoda H, Tanaka T, Inagawa S, Takeda H, Takehara Y, Isogai S, Sakahara H (2001) Dynamic gadolinium-enhanced MR imaging of pituitary adenomas: usefulness of sequential sagittal and coronal plane images. Eur J Radiol 39:139-146
26. Jagannathan J, Sheehan JP, Jane JA Jr (2007) Evaluation and management of Cushing syndrome in cases of negative sellar magnetic resonance imaging. Neurosurg Focus 23:E3

27. Batista D, Courkoutsakis NA, Oldfield EH, Griffin KJ, Keil M, Patronas NJ, Stratakis CA (2005) Detection of adrenocorticotropinsecreting pituitary adenomas by magnetic resonance imaging in children and adolescents with Cushing disease. J Clin Endocrinol Metab 90:5134-5140

28. Portocarrero-Ortiz L, Bonifacio-Delgadillo D, SotomayorGonzalez A, Garcia-Marquez A, Lopez-Serna R (2010) A modified protocol using half-dose gadolinium in dynamic 3Tesla magnetic resonance imaging for detection of ACTHsecreting pituitary tumors. Pituitary 13:230-235

29. Hall WA, Luciano MG, Doppman JL, Patronas NJ, Oldfield EH (1994) Pituitary magnetic resonance imaging in normal human volunteers: occult adenomas in the general population. Ann Intern Med 120:817-820

30. Findling JW, Kehoe ME, Shaker JL, Raff H (1991) Routine inferior petrosal sinus sampling in the differential diagnosis of adrenocorticotropin (ACTH)-dependent Cushing's syndrome: early recognition of the occult ectopic ACTH syndrome. J Clin Endocrinol Metab 73:408-413

31. Oldfield EH, Doppman JL, Nieman LK, Chrousos GP, Miller DL, Katz DA, Cutler GB Jr, Loriaux DL (1991) Petrosal sinus sampling with and without corticotropin-releasing hormone for the differential diagnosis of Cushing's syndrome. N Engl J Med 325:897-905

32. Newell-Price J, Bertagna X, Grossman AB, Nieman LK (2006) Cushing's syndrome. Lancet 367:1605-1617

33. Lad SP, Patil CG, Laws ER Jr, Katznelson L (2007) The role of inferior petrosal sinus sampling in the diagnostic localization of Cushing's disease. Neurosurg Focus 23:E2

34. Newell-Price J, Trainer P, Besser M, Grossman A (1998) The diagnosis and differential diagnosis of Cushing's syndrome and pseudo-Cushing's states. Endocr Rev 19:647-672

35. Swearingen B, Katznelson L, Miller K, Grinspoon S, Waltman A, Dorer DJ, Klibanski A, Biller BM (2004) Diagnostic errors after inferior petrosal sinus sampling. J Clin Endocrinol Metab 89:3752-3763

36. Shiu PC, Hanafee WN, Wilson GH, Rand RW (1968) Cavernous sinus venography. Am J Roentgenol Radium Ther Nucl Med 104:57-62

37. Benndorf G, Campi A (2002) Aberrant inferior petrosal sinus: unusual transvenous approach to the cavernous sinus. Neuroradiology 44:158-163

38. Oldfield EH, Chrousos GP, Schulte HM, Schaaf M, McKeever PE, Krudy AG, Cutler GB Jr, Loriaux DL, Doppman JL (1985) Preoperative lateralization of ACTH-secreting pituitary microadenomas by bilateral and simultaneous inferior petrosal venous sinus sampling. N Engl J Med 312:100-103

39. Seiler RW, Mariani L (2000) Sellar reconstruction with resorbable vicryl patches, gelatin foam, and fibrin glue in transsphenoidal surgery: a 10-year experience with 376 patients. J Neurosurg 93:762-765

40. Prevedello DM, Pouratian N, Sherman J, Jane JA Jr, Vance ML, Lopes MB, Laws ER Jr (2008) Management of Cushing's disease: outcome in patients with microadenoma detected on pituitary magnetic resonance imaging. J Neurosurg 109:751-759

41. Mamelak AN, Dowd CF, Tyrrell JB, McDonald JF, Wilson CB (1996) Venous angiography is needed to interpret inferior petrosal sinus and cavernous sinus sampling data for lateralizing adrenocorticotropin-secreting adenomas. J Clin Endocrinol Metab $81: 475-481$

42. Oliverio PJ, Monsein LH, Wand GS, Debrun GM (1996) Bilateral simultaneous cavernous sinus sampling using corticotropin- 
releasing hormone in the evaluation of Cushing disease. AJNR Am J Neuroradiol 17:1669-1674

43. Doppman JL, Nieman LK, Chang R, Yanovski J, Cutler GB Jr, Chrousos GP, Oldfield EH (1995) Selective venous sampling from the cavernous sinuses is not a more reliable technique than sampling from the inferior petrosal sinuses in Cushing's syndrome. $\mathrm{J}$ Clin Endocrinol Metab 80:2485-2489

44. Lefournier V, Martinie M, Vasdev A, Bessou P, Passagia JG, Labat-Moleur F, Sturm N, Bosson JL, Bachelot I, Chabre O (2003) Accuracy of bilateral inferior petrosal or cavernous sinuses sampling in predicting the lateralization of Cushing's disease pituitary microadenoma: influence of catheter position and anatomy of venous drainage. J Clin Endocrinol Metab $88: 196-203$

45. Friedman TC, Yanovski JA, Nieman LK, Doppman JL, Cutler GB Jr, Oldfield EH, Gold PM, Chrousos GP, Kalogeras KT (1996) Inferior petrosal sinus arginine vasopressin concentrations in normal volunteers and patients with Cushing's disease. J Clin Endocrinol Metab 81:3068-3072
46. Joshi SM, Hewitt RJ, Storr HL, Rezajooi K, Ellamushi H, Grossman AB, Savage MO, Afshar F (2005) Cushing's disease in children and adolescents: 20 years of experience in a single neurosurgical center. Neurosurgery 57:281-285

47. Semple PL, Vance ML, Findling J, Laws ERJ (2000) Transsphenoidal surgery for Cushing's disease: outcome in patients with a normal magnetic resonance imaging scan. Neurosurgery 46:553-559

48. Bonelli FS, Huston J 3rd, Carpenter PC, Erickson D, Young WF Jr, Meyer FB (2000) Adrenocorticotropic hormone-dependent Cushing's syndrome: sensitivity and specificity of inferior petrosal sinus sampling. AJNR Am J Neuroradiol 21:690-696

49. Graham KE, Samuels MH, Nesbit GM, Cook DM, O'Neill OR, Barnwell SL, Loriaux DL (1999) Cavernous sinus sampling is highly accurate in distinguishing Cushing's disease from the ectopic adrenocorticotropin syndrome and in predicting intrapituitary tumor location. J Clin Endocrinol Metab 84:1602-1610

50. Gandhi CD, Meyer SA, Patel AB, Johnson DM, Post KD (2008) Neurologic complications of inferior petrosal sinus sampling. AJNR Am J Neuroradiol 29:760-765 